\title{
A Review of Methods for the Manufacture of Residential Roofing Materials
}

\author{
Hashem Akbari, Ronnen Levinson, and Paul Berdahl \\ Heat Island Group \\ Lawrence Berkeley National Laboratory \\ Berkeley, CA 94720
}

\author{
A Report Prepared for: \\ California Energy Commission PIER Program \\ Program Manager: Nancy Jenkins \\ Project Manager: Chris Scruton
}

June 2003

* This study was supported by funding from the California Energy Commissions (CEC) through the U.S. Department of Energy under contract DE-AC03-76SF00098. 


\section{DISCLAIMER}

This document was prepared as an account of work sponsored by the United States Government. While this document is believed to contain correct information, neither the United States Government nor any agency thereof, nor The Regents of the University of California, nor any of their employees, makes any warranty, express or implied, or assumes any legal responsibility for the accuracy, completeness, or usefulness of any information, apparatus, product, or process disclosed, or represents that its use would not infringe privately owned rights. Reference herein to any specific commercial product, process, or service by its trade name, trademark, manufacturer, or otherwise, does not necessarily constitute or imply its endorsement, recommendation, or favoring by the United States Government or any agency thereof, or The Regents of the University of California. The views and opinions of authors expressed herein do not necessarily state or reflect those of the United States Government or any agency thereof or The Regents of the University of California. 


\section{ACKNOWLEDGEMENTS}

This study was supported by funding from the California Energy Commission (CEC) through the U. S. Department of Energy under contract DE-AC03-76SF00098. The authors would like to acknowledge the support and guidance of the CEC project Manager Chris Scruton, as well as the contributions of our industrial partners including Mr. Gus Freshwater (vice president and general manager of the Elk Corporation shingle manufacturing plant in Shafter, CA); Dr. Louis Hahn and Mr. Keith Tellman (both from Elk Corporation, Texas Headquarters); Dr. Christopher Gross (3M Industrial Mineral Division); Dr. Ingo Joedicke (ISP headquarter in Hagerstown MD); Mr. David Carlson (manager of ISP granule plant in Ione, CA); Mr. Steve Perry (the plant shift facilitator at the Steelscape coil-coating plant in Rancho Cucamonga, CA); Ms. Michelle Vondran (formerly with BASF, now with Steelscape), Mr. John Marotta, and Mr. Jay Lewis (both with BASF); Mr. Jerry Vandewater and Mr. Jim Smith (both from MonierLifetile), and Mr. Yoshihiro Suzuki (general manager and director of MCA Tile in Corona, CA). 


\title{
A Review of Methods for the Manufacture of Residential Roofing Materials ${ }^{\star}$
}

\author{
Hashem Akbari, Ronnen Levinson, and Paul Berdahl \\ Heat Island Group \\ Lawrence Berkeley National Laboratory \\ Berkeley, CA 94720
}

\begin{abstract}
Shingles, tiles, and metal products comprise over $80 \%$ (by roof area) of the California roofing market ( $54-58 \%$ fiberglass shingle, $8-10 \%$ concrete tile, $8-10 \%$ clay tile, $7 \%$ metal, $3 \%$ wood shake, and $3 \%$ slate). In climates with significant demand for cooling energy, increasing roof solar reflectance reduces energy consumption in mechanically cooled buildings, and improves occupant comfort in non-conditioned buildings. This report examines methods for manufacturing fiberglass shingles, concrete tiles, clay tiles, and metal roofing. The report also discusses innovative methods for increasing the solar reflectance of these roofing materials. We have focused on these four roofing products because they are typically colored with pigmented coatings or additives. A better understanding of the current practices for manufacturing colored roofing materials would allow us to develop cool colored materials creatively and more effectively.
\end{abstract}

\footnotetext{
* This study was supported by funding from the California Energy Commissions (CEC) through the U.S. Department of Energy under contract DE-AC03-76SF00098.
} 


\section{Introduction}

According to Western Roofing Insulation and Siding magazine (2002), the total value of the 2002 projected residential roofing market in 14 western U.S. states (AK, AZ, CA, CO, HI, ID, MT, NV, NM, OR, TX, UT, WA, and WY) was about $\$ 3.6$ billion (B). We estimate that $40 \%$ (\$1.4B) of that amount was spent in California. The lion's share of residential roofing expenditure was for fiberglass shingle, which accounted for $\$ 1.7 \mathrm{~B}$, or $47 \%$ of sales. Concrete and clay roof tile made up $\$ 0.95 \mathrm{~B}(27 \%)$, while wood, metal, and slate roofing collectively represented another $\$ 0.55 \mathrm{~B}(15 \%)$. The value of all other roofing projects was about $\$ 0.41 \mathrm{~B}$ $(11 \%)$.

We estimated roofing area market shares by assuming that roofing projects involving concrete tile, clay tile, wood shingle/shake, or slate were 50\% (Estimate 1) to 100\% (Estimate 2) more expensive than those using other roofing materials, such as shingle, metal, or membrane. This suggests that the roofing market area distribution was $54-58 \%$ fiberglass shingle, $8-10 \%$ concrete tile, $8-10 \%$ clay tile, $7 \%$ metal, $3 \%$ wood shake, and $3 \%$ slate (Table 1 ).

The functional distribution of the steep-slope roofing market in 2002 (including both residential and small-commercial buildings) was about $60 \%$ replacement, $25 \%$ new construction, and $15 \%$ repair and maintenance.

This paper examines methods for manufacturing fiberglass shingles, concrete tiles, clay tiles, and metal roofing that constitute over $80 \%$ of all roofing materials by both expenditure and area. Table 2 briefly describes each technology. We have focused on these four roofing products because they are typically colored with pigmented coatings or additives. We do not discuss production of wood and slate roofing. A better understanding of the current practices for manufacturing colored roofing materials would allow us to develop cool colored materials creatively and more effectively. The paper also discusses innovative methods for increasing the solar reflectance of these roofing materials.

\section{Methodology}

We reviewed the literature for production of roofing materials and visited several roofing material manufacturing plants.

\section{Literature review}

The following briefly summarizes several pertinent sources of information about roofing manufacturing methods available from web sites, articles, papers, patents, and books. In The Science and Technology of Traditional and Modern Roofing Systems, Laaly (1992) provides an overview of the production and application of various roofing materials. A web site of the National Park Services (NPS 2003) also provides the historical backgrounds of several roofing materials, including asbestos-cement shingle, asphalt shingle, clay tile, composition (built-up roofing), metal, slate, and wood shingle.

The Department of Health and Human Services (DHHS 2001) and the Environmental Protection Agency (EPA 1995) have each prepared extensive documents discussing various manufacturing methods for asphalt roofing products. These focus on environmental pollution, and do not address the effects of roof reflectivity on heating and cooling energy use and on roof durability. 
Brown (1960) and Jewett et al. (1994) detail in chapters of 1960 and 1994 editions of Industrial Mineral and Rocks the manufacture of the colored roofing granules that are used in fiberglass and organic shingle roofs. Though these texts cover a wide range of technical and marketing issues related to the manufacture and production of colored granules, they provide limited information on granule coloring techniques. Joedicke (1997 and 2002) discusses this topic in greater detail.

Finally, Paris and Chusid $(1997,1999)$ briefly describe methods for coloring concrete products using powder, liquid, and granulated pigments. They also discuss issues related to the durability of colored concrete.

\section{Plant visits}

We visited a shingle plant, a metal roofing plant, and a clay tile plant in southern California; and a granule production plant and a concrete tile plant in northern California. Brief discussions of these plants are provided in the Appendix.

Table 1. 2002 Project residential roofing market in the U.S. western region ${ }^{a}$ surveyed by Western Roofing (2002).

\begin{tabular}{|l|c|c|c|c|}
\hline \multirow{2}{*}{ Roofing Type } & \multicolumn{2}{|c|}{ Market share by \$ } & \multicolumn{2}{c|}{ Market share by roofing area (\%) } \\
& \$B & $\%$ & Estimate 1 & Estimate 2 \\
\hline Fiberglass Shingle & 1.70 & 47.2 & 53.6 & 57.5 \\
Concrete Tile & 0.50 & 13.8 & 10.4 & 8.4 \\
Clay Tile & 0.45 & 12.6 & 9.5 & 7.7 \\
Wood Shingle/Shake & 0.17 & 4.7 & 3.6 & 2.9 \\
Metal/Architectural & 0.21 & 5.9 & 6.7 & 7.2 \\
Slate & 0.17 & 4.7 & 3.6 & 2.9 \\
Other & 0.13 & 3.6 & 4.1 & 4.4 \\
SBC Modified & 0.08 & 2.1 & 2.4 & 2.6 \\
APP Modified & 0.07 & 1.9 & 2.2 & 2.3 \\
Metal/Structural & 0.07 & 1.9 & 2.2 & 2.3 \\
Cementitious & 0.04 & 1.1 & 1.2 & 0.6 \\
Organic Shingles & 0.02 & 0.5 & 0.6 & $\mathbf{1 0 0}$ \\
\hline Total & $\mathbf{3 . 6 0}$ & $\mathbf{1 0 0}$ & $\mathbf{1 0 0}$ & \\
\hline
\end{tabular}

a. The 14 states included in the U.S. western region are AK, AZ, CA, CO, HI, ID, MT, NV, NM, OR, TX, UT, WA, and WY. 
Table 2. Residential-building roofing technologies and their market shares in the 14-state U.S. western region surveyed by Western Roofing (2002).

\begin{tabular}{|c|c|c|c|}
\hline \multirow[b]{2}{*}{ Technology } & \multirow[b]{2}{*}{ Description } & \multicolumn{2}{|c|}{ MARKET SHARE $^{a}$} \\
\hline & & Sales & Area $^{b}$ \\
\hline $\begin{array}{l}\text { Asphalt } \\
\text { Shingle }\end{array}$ & $\begin{array}{l}\text { Asphalt is a dark brown to black cementitious material, solid or semisolid, in which the } \\
\text { predominant constituents are naturally occurring or petroleum-derived bitumens. It is } \\
\text { used as a weatherproofing agent. The term asphalt shingle is generically used for } \\
\text { both fiberglass and organic shingles. There are two grades of asphalt shingles: (1) } \\
\text { standard, a.k.a. 3-tab; and (2) architectural, a.k.a. laminated or dimensional. Asphalt } \\
\text { shingles come in various colors. }\end{array}$ & $47.7 \%$ & $58.1 \%$ \\
\hline \multirow[t]{2}{*}{ Examples } & $\begin{array}{l}\text { Fiberglass shingles, commonly known as "asphalt shingles," consist of fiber mats that } \\
\text { are coated with asphalt and then covered with granules. Granules, a.k.a. mineral } \\
\text { granules or ceramic granules, are opaque naturally- or synthetically-colored } \\
\text { aggregates commonly used to surface cap sheets and shingles. }\end{array}$ & $47.2 \%$ & $57.5 \%$ \\
\hline & $\begin{array}{l}\text { Organic shingles have a thick cellulose base that is saturated in soft asphalt. This } \\
\text { saturation makes them heavier than fiberglass shingles, and less resistant to heat and } \\
\text { humidity, but more durable in freezing conditions. }\end{array}$ & $0.5 \%$ & $0.6 \%$ \\
\hline \multirow[t]{3}{*}{ Tile } & Usually made of concrete or clay. & $26.4 \%$ & $16.1 \%$ \\
\hline & $\begin{array}{l}\text { Concrete tile is a combination of sand, cement, and water; the water fraction depends } \\
\text { on the manufacturing process. Concrete tiles are either air-cured or auto-claved. Color } \\
\text { is added to the surface of the tile with a slurry coating process, or added to the } \\
\text { mixture during the manufacturing process. }\end{array}$ & $13.8 \%$ & $8.4 \%$ \\
\hline & $\begin{array}{l}\text { Clay tile is a combination of various clays and water. Color is added to the surface of } \\
\text { the tile with a slurry coating process before the tile is kiln-fired. }\end{array}$ & $12.6 \%$ & $7.7 \%$ \\
\hline Metal & Metal roofs can be classified as architectural or structural. & $7.8 \%$ & $9.5 \%$ \\
\hline \multirow[t]{2}{*}{ Examples } & $\begin{array}{l}\text { Architectural (hydrokinetic-watershedding) standing-seam roof systems are typically } \\
\text { used on steep slopes with relatively short panel lengths. They usually do not have } \\
\text { sealant in the seam because they are designed to shed water rapidly. They do not } \\
\text { provide structural capacity or load resistance, and their installation is less labor- } \\
\text { intensive because they have a solid substrate platform that makes installation easier. }\end{array}$ & $5.9 \%$ & $7.2 \%$ \\
\hline & $\begin{array}{l}\text { Structural (hydrostatic-watershedding) standing-seam roof systems are versatile metal } \\
\text { panel systems that can be used on both steep-and low-slope roofs and are designed } \\
\text { to be water-resistant. Most structural standing-seam systems include a factory-applied } \\
\text { sealant in the standing seams to help ensure water tightness. These panel systems } \\
\text { provide structural capacity and load resistance. }\end{array}$ & $1.9 \%$ & $2.3 \%$ \\
\hline Other & All other roofing materials that are not covered under the categories mentioned above. & $18.1 \%$ & $16.3 \%$ \\
\hline
\end{tabular}

a. California accounts for $38 \%$ of the market in the 14 states (AK, AZ, CA, CO, HI, ID, MT, NV, NM, OR, TX, UT, WA, and WY) that make up the western region surveyed by Western Roofing magazine.

$b$. The roof areas fractions are LBNL's estimates and are derived from product costs and market shares. 


\section{Manufacturing methods}

\section{Shingles}

\section{Production of colored granules}

Granules cover over $97 \%$ of the surface of a typical asphalt-soaked fiberglass shingle. Granules are applied to asphalt shingles for several reasons, including UV protection, coloration, ballasting, impact resistance, and fire resistance.

Granule manufacturing plants are typically sited near a quarry of suitable base rocks, including andesite, coal slag, diabase, metabasalt, nephaline syenite, quartzite, rhyodacite, rhyolite, and river gravel. The essential characteristics of the base rock include (1) opacity to ultraviolet light, to protect the asphalt from ultraviolet damage; (2) chemical and physical inertness, to provide resistance to acid rain, leaching, freeze/thaw, wet/dry cycling, oxidation and rusting; (3) low porosity, to improve physical strength, binding between coating and rock, and efficiency with which the pigment coating covers the surface; and (4) tolerance of high firing temperatures. Other necessary characteristics include moderate hardness, to remain intact during the granule coloring process; moderate density, to weight the shingle against wind lift; uniformity; and crush equidimensionally, to prevent directional embedment in the shingle manufacturing process, which changes shingle appearance.

In a roofing granule manufacturing plant, rocks blasted from quarries are crushed in several stages to create granule-size aggregate $(0.5$ to $2 \mathrm{~mm})$ (Figure 1$)$. In this process, the larger aggregates are recycled to the crushing system and the smaller debris is separated for other usage.

Once the granules are milled to the right size, they are transferred to the coloring plant. In the coloring plant, they are coated with a semi-ceramic color coating via a continuous process. The coating is a mixture of color pigments, sodium silicate, hydrated kaolin clay, and water. The preheated granules are mixed and tumbled with coating sufficient to cover the surface. The wet coated granules are then transferred to a rotary kiln where they are gradually heated to $250-550{ }^{\circ} \mathrm{C}$ $\left(500-1000^{\circ} \mathrm{F}\right)$. This dehydrates and polymerizes the coating, forming an insoluble pigmented ceramic layer. The granules are then gradually cooled in a rotary cooler by sprayed water and circulated air. Finally, the pigmented granules are coated with mineral oil to control dust and to improve asphalt adhesion. The mineral oil typically evaporates within a few months.

The pigments used for colored granules must have certain properties, including stability at high temperature, chemical inertness, ease of dispersion, color consistency, weather stability, nontoxicity, and low cost. Common pigments used in roofing granules include titanium dioxide (white), zinc ferrite (yellow), red iron oxides, carbon black, chrome oxide (green), and ultramarine (blue). Typically, 2.3-2.7 kg (5-6 lb) of pigment is required per tonne of granules to create a single-layer coating. Multiple coatings are needed to increase pigment loading. Some granule manufacturing plants have parallel coloring lines that can also be used in series to apply multiple layers of coatings? to granules.

The granules (both colored and uncolored) are transported to shingle manufacturing companies by road and rail. 


\section{Production of shingles}

Fiberglass asphalt shingles have three major components: fiberglass mat, asphalt (with additive mineral stabilizer fillers), and granules (colored and uncolored). In a typical plant, the fiberglass mat is fed into a roll coater that applies layers of stabilized coating asphalt to the top and bottom surfaces of the webbing sheet. Stabilized coating asphalt is harder and more viscous than straight asphalt, and has a higher softening point. The mineral stabilizer used in asphalt roofing applications is an inorganic material, typically a crushed rock. It may consist of finely divided limestone, silica, slate dust, dolomite, or other minerals. Because this material is inorganic, it is less susceptible than asphalt to temperature change and fire. These properties are important for shingle manufacturing. Asphalt with stabilizer provides uniform and consistent properties within the climatic temperature range. Essentially, the stabilizer reduces viscosity in colder weather (making the shingle less brittle) and increases viscosity in warmer weather (increasing the softening point). In addition, the mineral stabilizer decreases the flammability of asphalt, thus allowing a higher fire rating of the shingle.

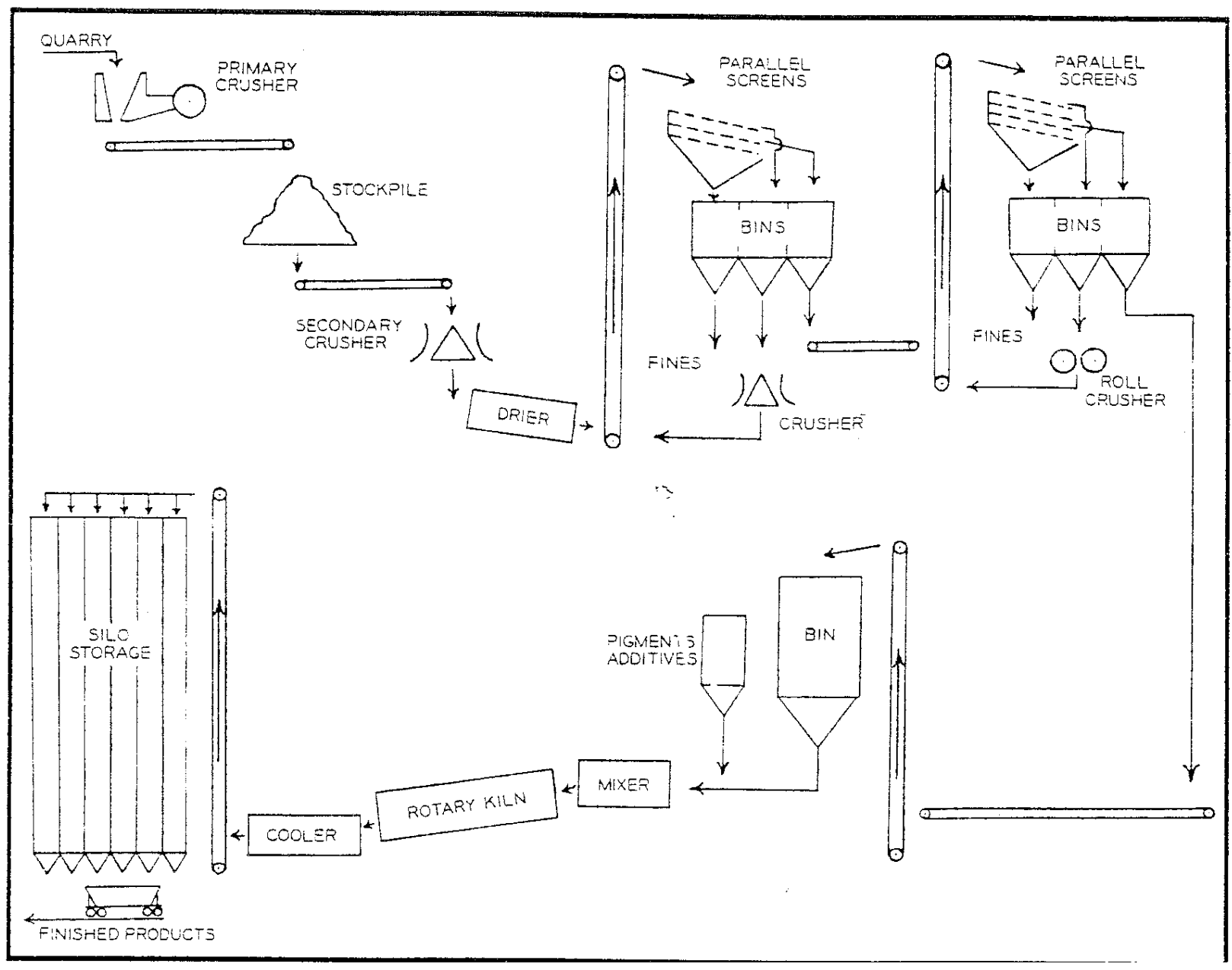

Figure 1. Schematic of a granule production plant. (Figure courtesy of Jewett, C.L., et al. 1994) 
The "filled" or "stabilized" coating asphalt applied at the coater is produced in the mixer, which is usually positioned above the manufacturing line at the coater. Coating asphalt, typically at $200-270{ }^{\circ} \mathrm{C}\left(400-520^{\circ} \mathrm{F}\right)$, is piped into the mixer, and the mineral stabilizer is added. To eliminate moisture problems and to help maintain the temperature above $180^{\circ} \mathrm{C}\left(360^{\circ} \mathrm{F}\right)$ for proper coating consistency in the mixer, the mineral stabilizer is dried and preheated before it is added.

The weight of the finished product is controlled by the thickness of the asphalt coating. The distance between the coating rolls controls the amount of coating applied to the substrate. Most modern plants are equipped with automatic scales or profile scanners that monitor the sheets during the manufacturing process and warn the operator when too much or too little coating is being applied.

Colored and uncolored granules are applied in a section of the manufacturing line that usually consists of a multi-compartmented granule hopper, two parting agent hoppers, and two large press rollers. The hoppers are fed through flexible hoses from one or more machine bins located above the production line. These machine bins (sometimes called surge bins) provide temporary storage. The granule hopper drops colored granules from its various compartments onto the top surface of the moving sheet of coated web in the sequence necessary to produce the desired color pattern on the roofing.

Next, the sheet is cooled by passing it over water-cooled rollers; water may also be sprayed directly onto the sheet to speed cooling. The final steps in the production of asphalt roofing shingles are cutting and packaging. After the shingles have been cut by machine, they are moved by roller conveyor to automatic packaging equipment. The packaged shingles are then stacked on pallets and transferred by forklift to storage areas or waiting trucks. Photos of various stages of the process and schematic of the total process are shown in Figure 2 and Figure 3. 


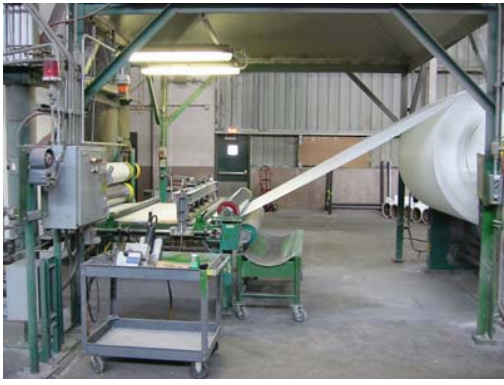

(a)

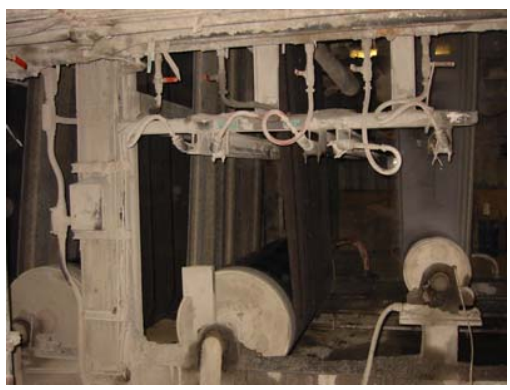

(d)

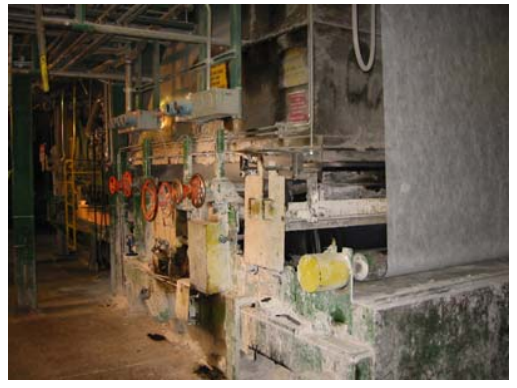

(b)

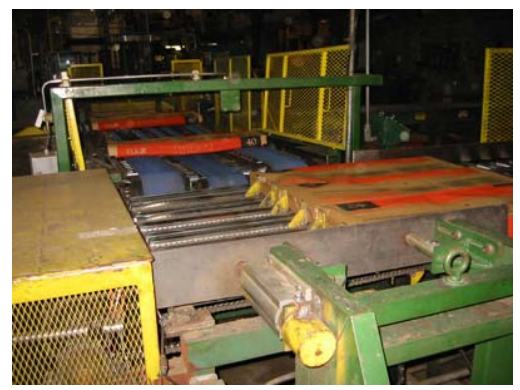

(e)

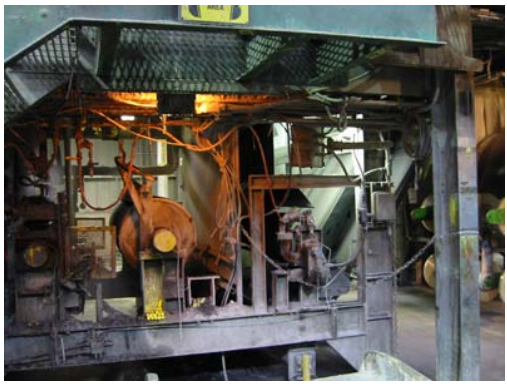

(c)

Figure 2. Shingle manufacturing processes: (a) fiberglass mat is fed into the line; (b) fiberglass enters the shingle production machinery; (c) fiberglass is soaked in asphalt and filler, then granules are roller-applied to both sides of the shingles; (d) shingle rolls are water-cooled by wet rollers; (e) cut and stacked shingles are packaged for shipping. 


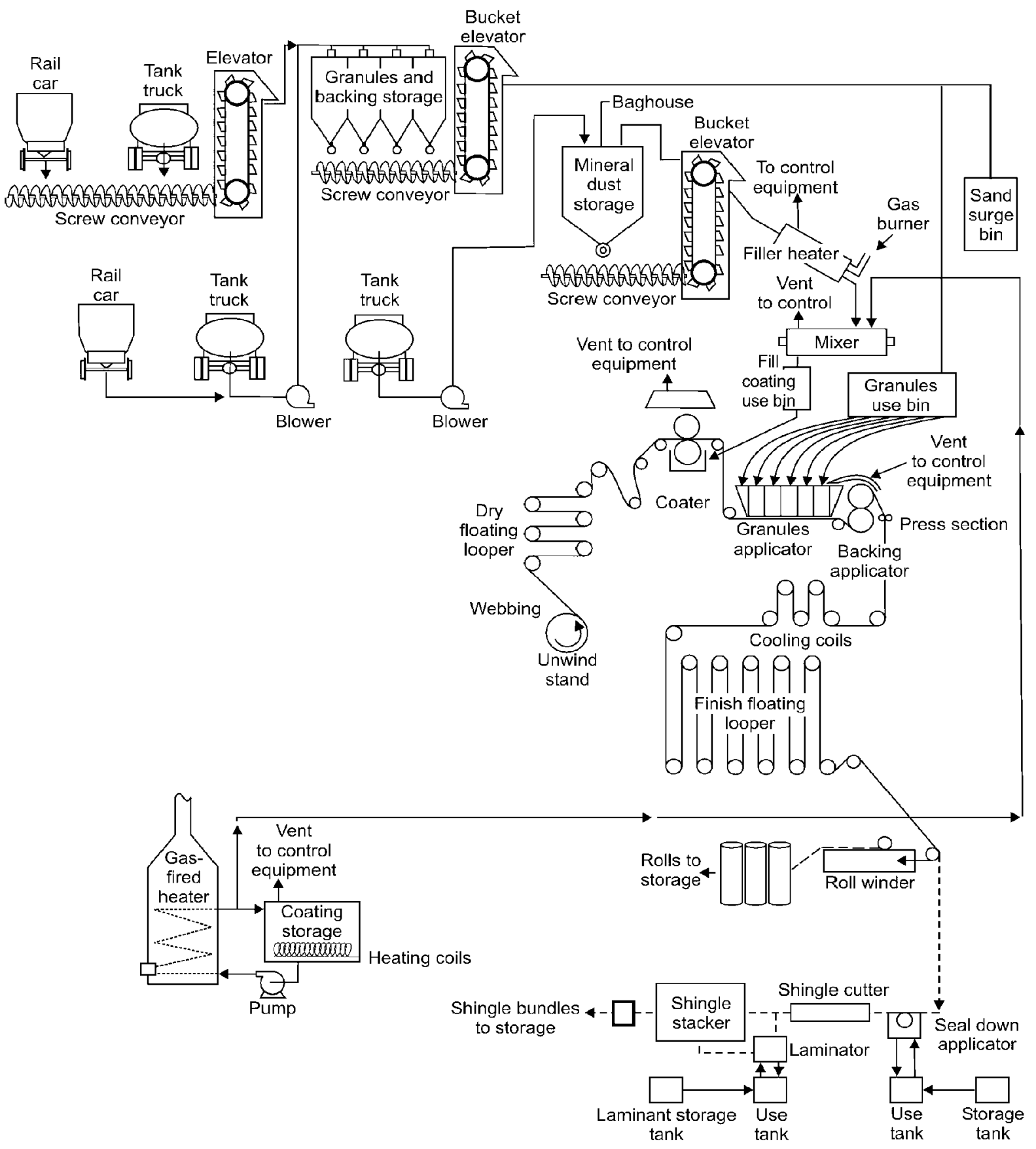

Figure 3. Schematic of a fiberglass shingle production plant. (Figure courtesy of DHHS 2001) 


\section{Clay tiles}

Clay tile production begins by mixing and crushing various raw clay materials. For example, the raw clays used at MCA Tile, Inc. include "yellow shell clay" (a clay with medium plasticity having high heat resistance, permitting vertical firing without warping); "apple clay" (a clay with high plasticity and low heat resistance); and "AAA clay" (a low shrinkage, medium heat resistance clay, with high iron content to make the tile red).

The raw clays are thoroughly mixed with water and aged for 4-5 days. The aging process allows the dry material to fully absorb the moisture, improving plasticity. This increases yields from the extrusion process and thus lowers the unit production cost.

Several extrusion machines and dies are employed to produce clay tiles of various shapes. Prior to extrusion, the clay flows through a vacuum chamber to remove air, preventing cracking of tiles during the firing process. This process is also very important for proper vitrification (conversion to a glassy state), which makes the tile weather resistant (i.e., resistant to freezing/thawing and salt intrusion; see Standard Specification for Clay Roof Tiles: ASTM C-1167 for more detail). An automated cutter at the end of each extruder cuts the tile to the desired size, and trims the edges. The wet extruded tile is then dried in a sequence of temperature-controlled chambers for about 24 hours. By reducing the excessive moisture in the tiles, this drying process reduces the probability of cracks when the tile is fired. The drying process typically starts with circulating ambient air at a temperature of about $20-30{ }^{\circ} \mathrm{C}$, gradually increasing the temperature to about $90{ }^{\circ} \mathrm{C}$ using waste heat from the kiln-cooling process. Drying reduces the tile's mass moisture content from $15 \%$ to less than $1 \%$.

The dry raw tiles are inspected for defects before they are sprayed with glossy or matte glazes. The glazing is a mixture of water, pigments and clay additives. For the glossy finish, frits (glassy silicates), clay and color glazed materials are added to the glazing mixture. The glazed tiles are positioned in vertical stacks or in a "standing up" position, with typically $1.25 \mathrm{~cm}(1 / 2$ ") spacers to allow an even heat distribution in the kiln. Even heating yields evenly colored tiles with good mechanical properties.

The glazed tiles are then passed through a kiln fired for 14-20 hours, depending upon the production schedule. The kiln has three stages: preheat, heating and cooling. In the preheating zone, the tiles are gradually heated to about $700{ }^{\circ} \mathrm{C}$ by warm drawn air from the heating zone. In the heating zone, the tiles are directly fired for about 4 hours by gas flame, reaching a maximum temperature of about $1050{ }^{\circ} \mathrm{C}$. Then the tiles are gradually cooled to about $300-400{ }^{\circ} \mathrm{C}$ by drawing outside air through the kiln. The clay tile is ready to ship as soon as it is removed from the kiln and cools to ambient temperature - no curing is required. The clay tile colors are permanent and do not fade with exposure to the sun. Photos of several steps in the process are shown in Figure 4. 


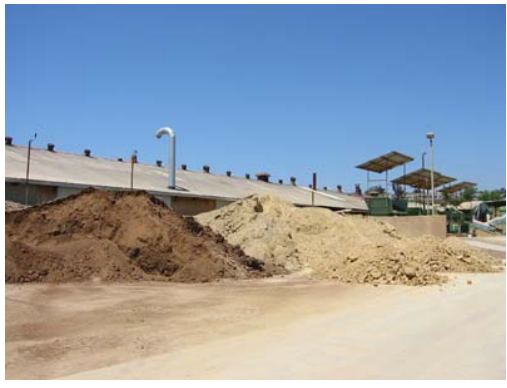

(a)

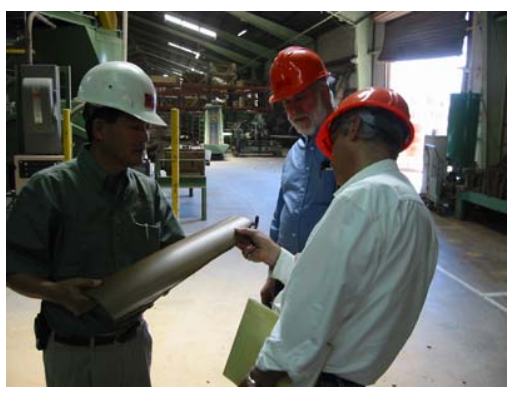

(d)

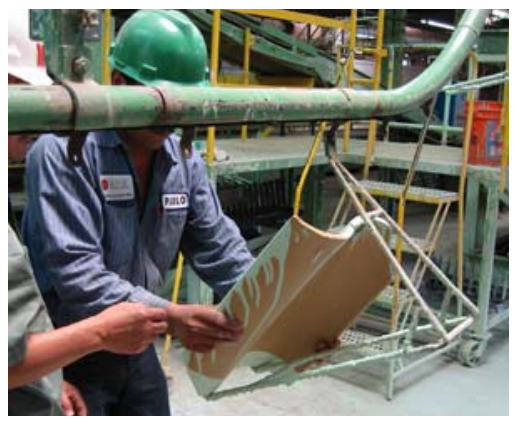

(g)

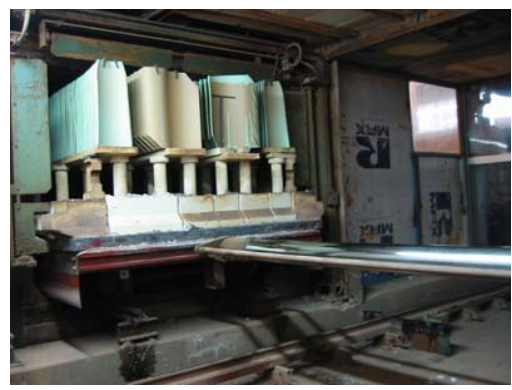

(j)

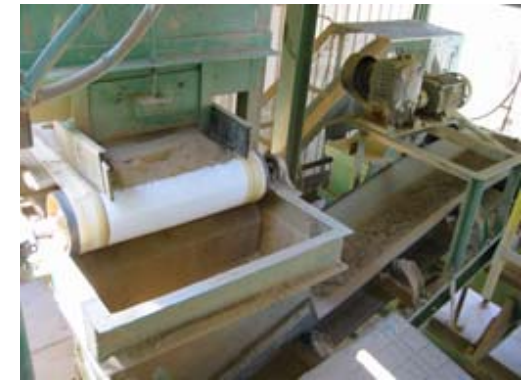

(b)

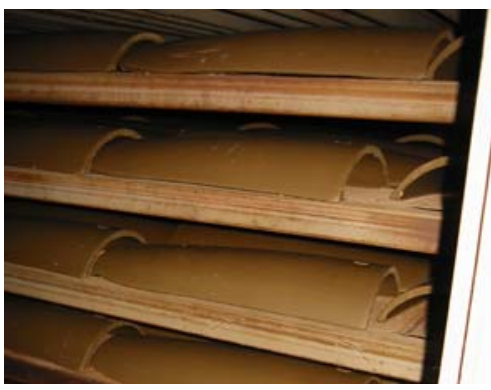

(e)

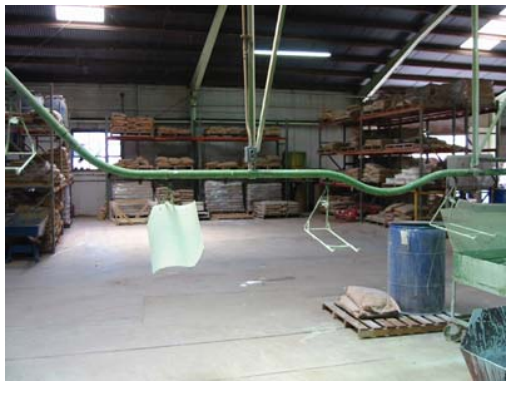

(h)

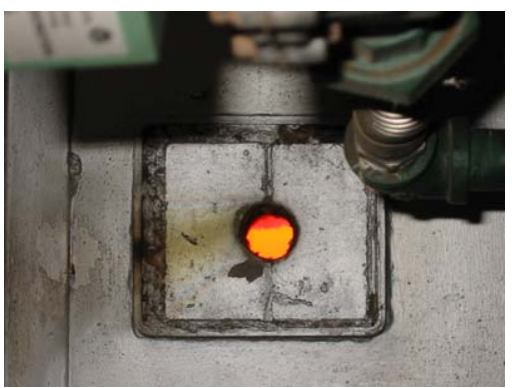

(k)

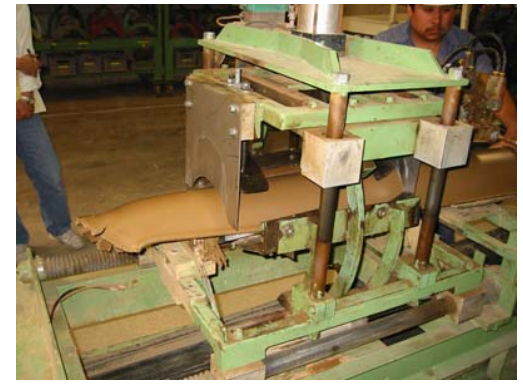

(c)

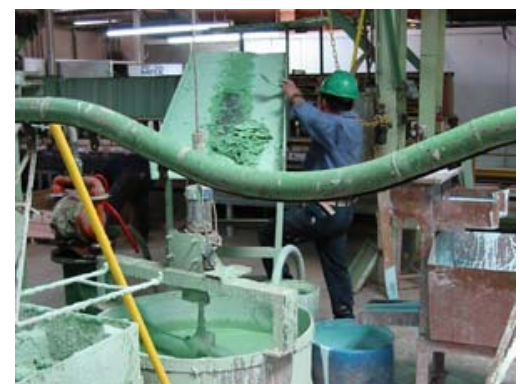

(f)

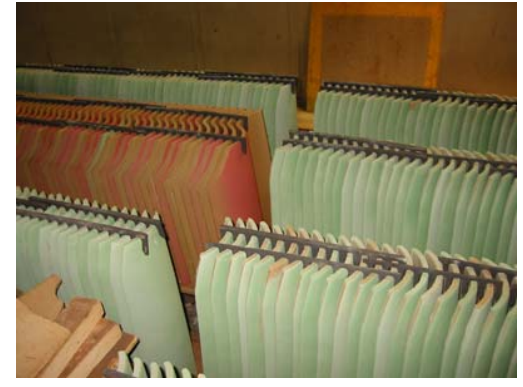

(i)

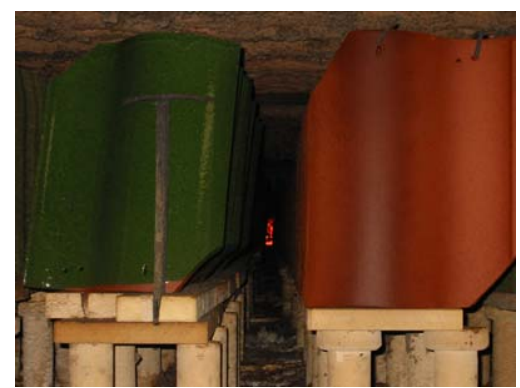

(1)

Figure 4 (I of II).Clay tile manufacturing processes: $(a, b)$ production begins by mixing and crushing raw clay components; (c,d) extrusion machines and molds produce variously shaped tiles; (e) the wet extruded tile is dried in a sequence of temperature-and humidity-controlled drying chambers for about 24 hours; $(f, g, h)$ the dry raw tiles are inspected for defects and sprayed with glossy or mat glazes; (i) the coated tiles are stacked with spacers (typically $1.25 \mathrm{~cm}$ ) to allow an even heat distribution in the kiln; $(j, k, l)$ the coated tiles are kiln-fired for 14-20 hours. 


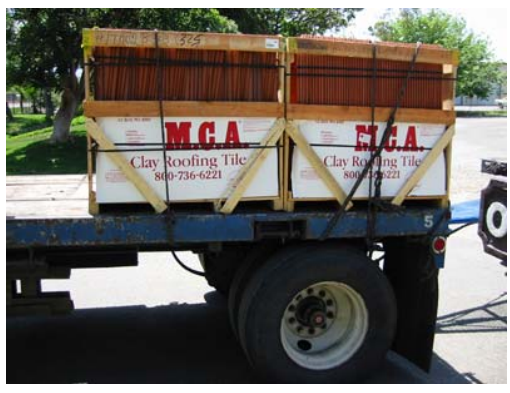

(m)

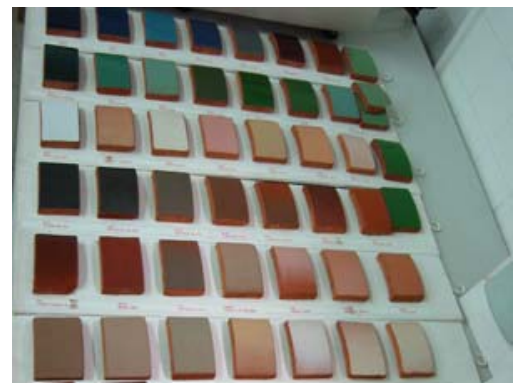

(n)

Figure 4 (II of II). Clay tile manufacturing processes: $(\mathrm{m})$ the finished tiles are shipped to customers. Figure (n) shows various tile samples.

\section{Concrete tiles}

Sand, cementitious materials, limestone fillers, and water are the main ingredients (by mass) of concrete tiles (see Figure 5). Pigments are added for color and polymers are used as a water resistant coating on the tile surface. Pigments are typically added to the surface in a slurry coat comprised of pigment, cement, silica and water. Finished concrete tiles may also be painted. The major components contributing to the cost are cementitious materials, sand, polymer coating, and pigments. Pigments are typically added to the surface in a slurry coat comprised of pigment, cement, silica and water. Tiles may also be painted.

Concrete tile production begins by mixing aggregate (sand) and fillers (see Figure 6). Sand is pre-washed to remove dirt contaminants. Recycled aggregates and quarry waste are also used in the mixture. Milled calcium carbonate, an inexpensive material that improves the quality of concrete, is used as filler. Then the aggregate and filler are mixed with cementitious materials before water is added to the mixture. At this stage, pigments may be added to color the concrete mix. The ingredients are completely mixed before being fed to the molding machine.

Several machines and molds are employed to produce concrete tiles of various shapes (see Figure 7). The mold and the wet concrete tile run on a conveyor where the tiles are partially dried and polymeric a coating is applied to the surface before curing. The tiles and the mold are packed in a curing chamber for about four hours, where the concrete tile is cured and dried. The molds and tiles run through a separator that removes the molds. The dry raw tiles are inspected for defects before they are sprayed with colored coatings. The tiles are then covered with postcoating polymers. The coating is a mixture of water, pigments, and polymeric additives. The coated tiles are then dried, stacked, and packed for shipment. 


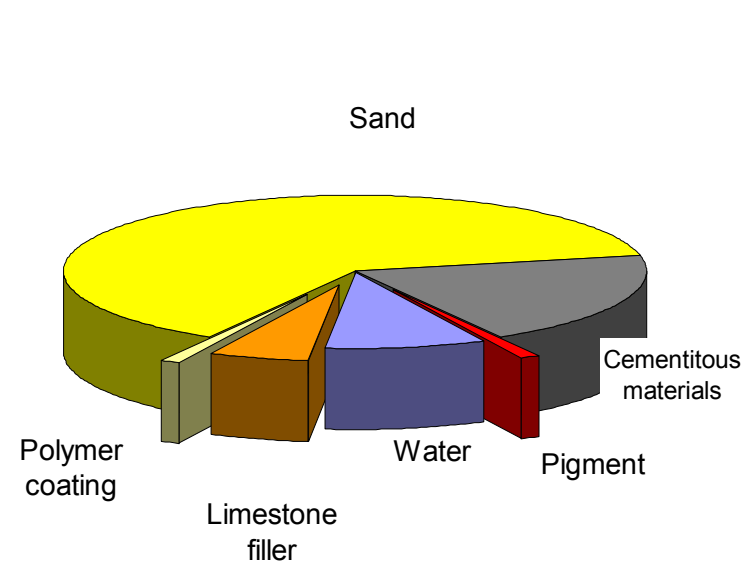

Based on mass
Cementitous

materials

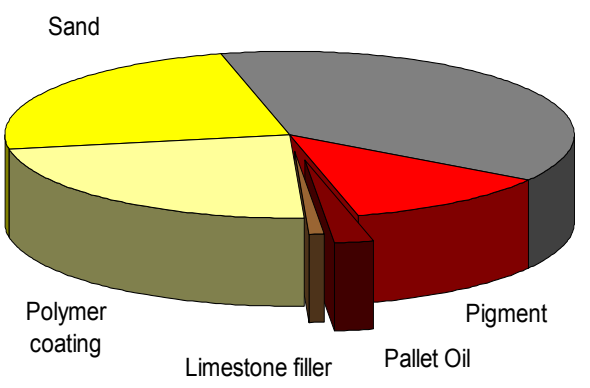

Based on cost

Figure 5. Typical composition of a concrete rooftile, by mass and by cost. (Figure courtesy of MonierLifetile)

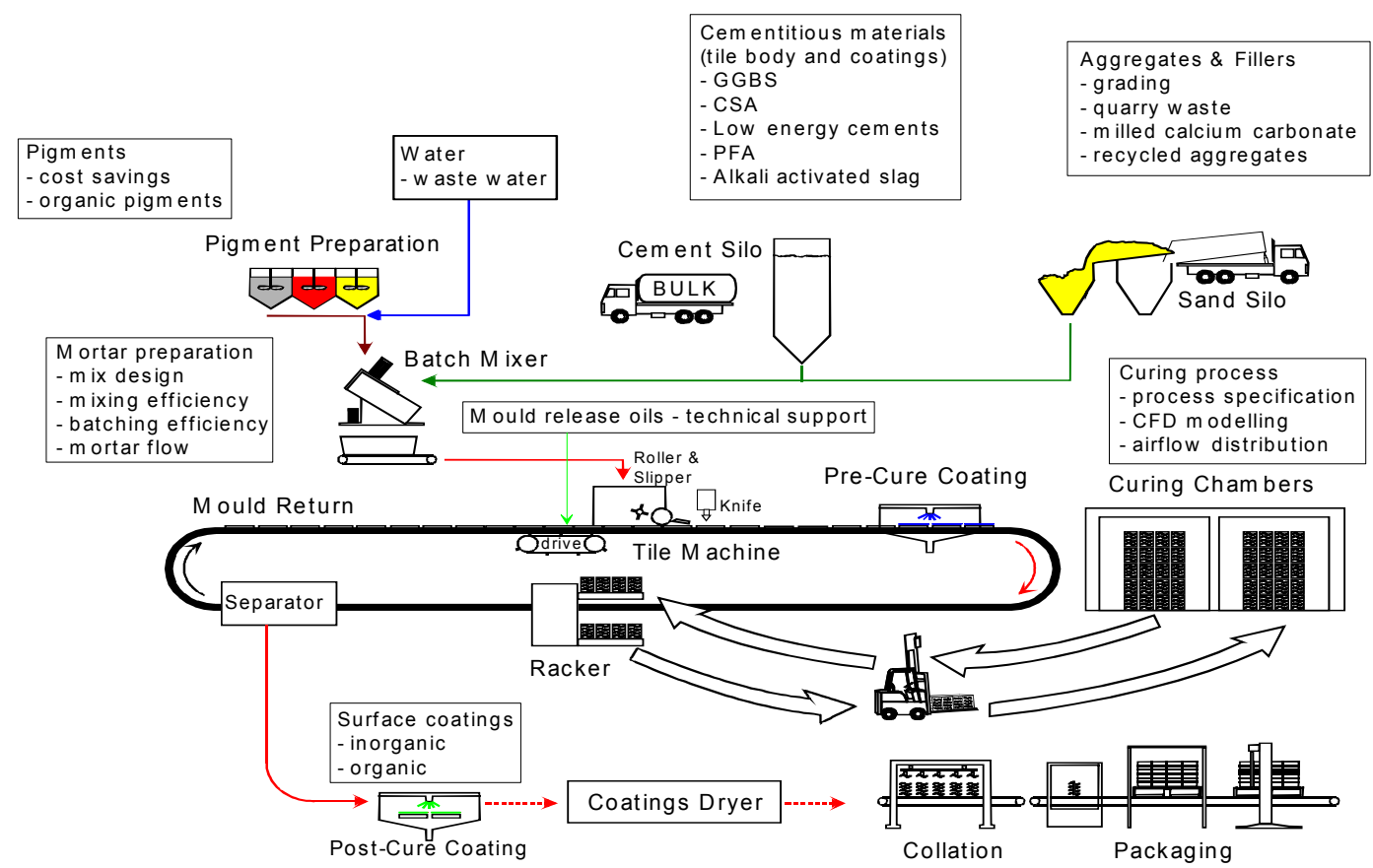

Figure 6. Schematic of a concrete rooftile production plant. (Figure courtesy of MonierLifetile) 


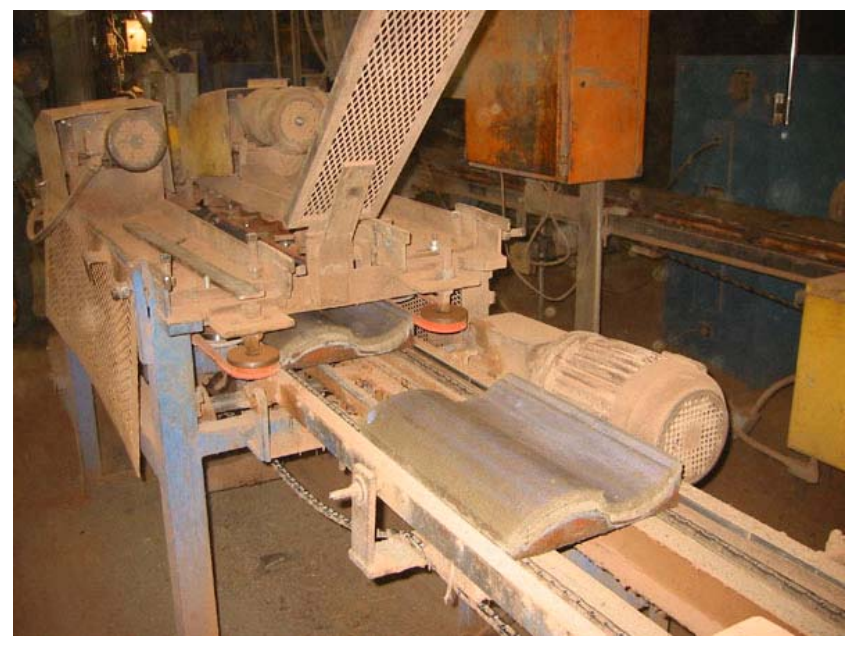

(a)

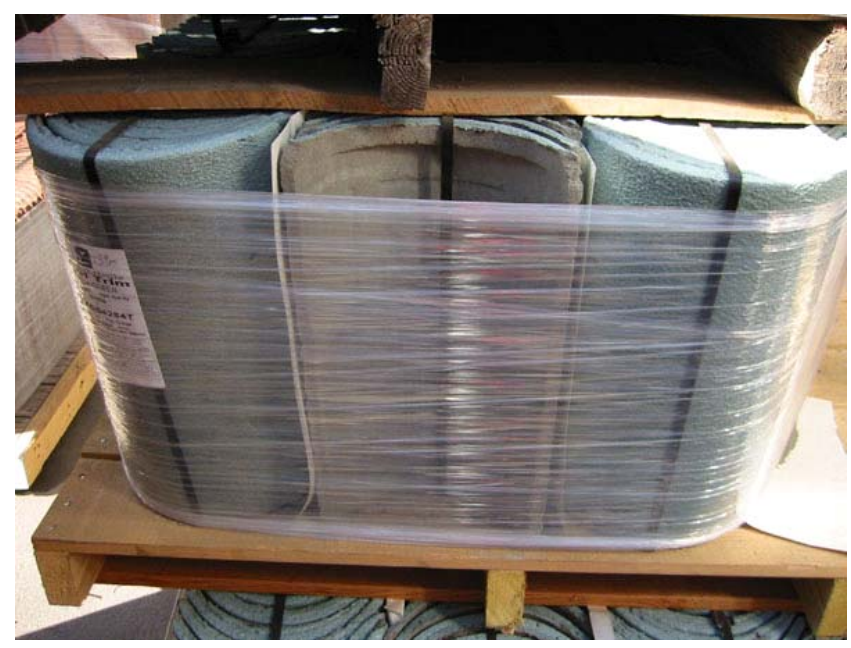

(b)

Figure 7. (a) Concrete tile molding machine and (b) final products ready to ship

\section{Metal roofing}

Metal production for the roofing industry may be divided into two phases: (1) coil coating plants, where raw metal coils are cleaned, metallic coated, primed, and paint coated (some facilities can both metallic coat and paint, while others only apply paint); and (2) metal forming plants, where the coated coils are either used to produce flat metal panels, or pressed into shapes that simulate non-metal roofing products (e.g., shake, slate, or tile).

\section{Coil coating plants}

Coil coaters produce rolled metals in the thickness, width, metal coating type and color specified by their customers, which include but are not limited to members of the roofing industry. An advanced metal coil plant typically has four major production lines: a pickle line, where the hotband coil ${ }^{\dagger}$ is uncoiled, is cleaned of oxides, has its edges trimmed to customer requirement, and is oiled in preparation of further processing; a cold mill line, where the pickled bands are reduced in thickness $65-80 \%$ to meet ordered thickness, are rolled to a suitable shape, and have texture applied to the surface; a metallic coating line, where the coils are cleaned again, a layer of metallic coating is applied, and the surface is treated for either painting or use of the product in a bare metal application; and a paint line where primer and finish coatings are applied. Many coil coaters consist of only a paint line; they do not process their own substrate.

\section{PICKLE LINE}

The raw material for this industry is typically a thick metal steel coil. The hot-band coil is pickled when it first arrives at the coating plant (Figure 8). There it is uncoiled and cleaned in a series of acid baths (stages 1-4) to ensure the proper surface for further processing, where it may be subjected to cold rolling and galvanizing (coating with zinc) or galvalumizing (coating with a zinc/aluminum alloy). The steel is then side-trimmed for width to the customer's specifications (stage 5). At the end of the pickle line process, the steel is re-coiled (stage 6) and ready to go on

\footnotetext{
${ }^{\dagger}$ Hot band coils are the result of steel slabs being elongated and rolled into coiled sheet of finite width and thickness; the temperature and amount of processing determine mechanical properties of the coil.
} 
to the cold rolling mill. The pickle line is capable of continuous production. One coil is processed while the other is prepared to be fed to the line.

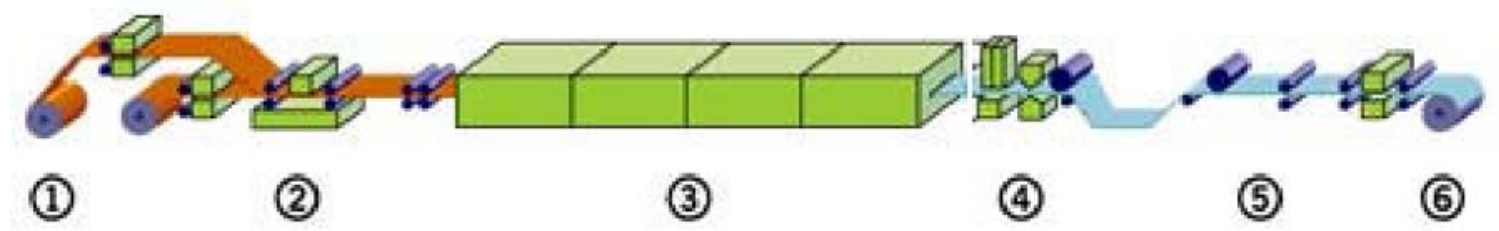

(1) Hot-rolled coil. The hot-rolled coil enters the pickle line.

(2) Stitcher. The end of one coil is joined to the beginning of the next coil.

(3) Acid tank. The band of steel is run through a series of acid tanks to remove rust, then rinsed in hot water.

(4) Side trimmer. The sides of the band are trimmed to the specified width.

(5) Shear. The stitches that connected two coils at the beginning of the line are cuts out.

(6) Tension reel. The steel is recoiled.

Figure 8. Metal coil coating: pickle line. (Figure courtesy of Steelscape 2003)

\section{COLD MiLl LiNe}

In the cold reversing mill (CRM) line, the thickness of the metal coil is reduced to specification by passing through pressure rolls (Figure 9). Larger scale cold mills pass the coil through a series of our or five rollers (Item 3 in Figure 9) to achieve the desired reduction in thickness. This way the full gauge reduction is achieved with one pass.

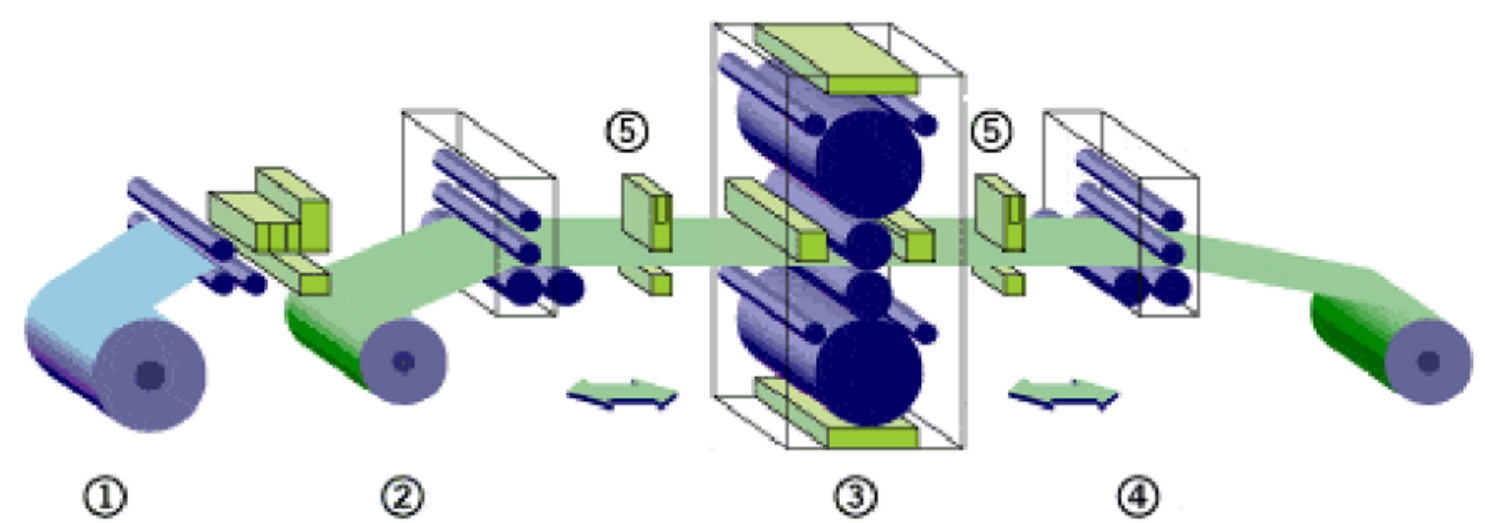

(1) Cold mill entry. The metal is uncoiled and passed forward through the rollers.

(2) Entry tension reel. After its initial pass through the CRM, the coil is prepared for the next pass through the rollers.

(3) Main roller set. Rollers apply pressure to the steel to reduce its thickness. The number of passes depended on the specification for the final thickness.

(4) Delivery tension reel. The steel is re-coiled.

(5) Thickness gauge.

Figure 9. Metal coil coating: cold mill line. (Figure courtesy of Steelscape 2003) 


\section{Metal COATING LiNe}

In the metal coating line, the steel coils are cleaned again, a layer of metallic coating (zinc of zinc/aluminum alloy) is applied, and the surface is treated either for painting or for use as bare metal (Figure 10). Coils from the cold mill line are fed to the entry reel (stage 1) and welded together (stage 2) for continuous line operation. The coil then passes through an accumulator tower (stage 3), after which the steel coils are cleaned in preparation for the metallic coating (stage 4) before being fed to the annealing furnace to achieve the desired mechanical properties (stage 5). Coming out of the furnace the strip is directly dipped into a molten bath of zinc or galvalume. The specified coating weight is achieved by air-wiping excess metal before it solidifies (stage 6). The hot-coated coil is then cooled (stage 7) and treated in a surfaceconditioning mill (stage 8). The process is very similar to the cold mill, but on a much smaller scale as the goal is to smooth the surface, not thin the coil. The steel is slightly elongated for uniform flatness by the tension leveler (stage 9). The surface can also be chemically treated (stage 10) and coated with a resin (stage 11) for bare metal applications.

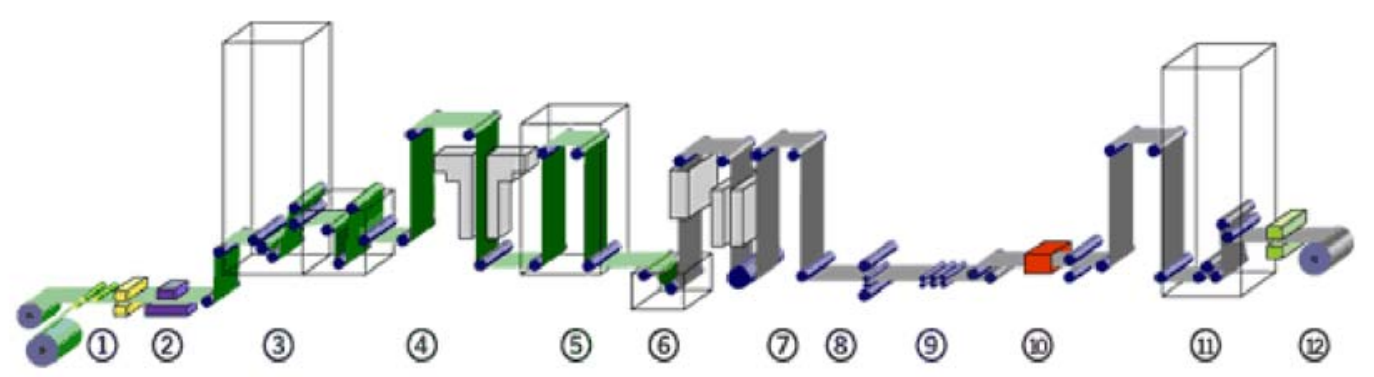

(1) Entry reel.

(2) Welder. The end of one coil is welded to the beginning of another for continuous operation.

(3) Entry accumulator tower.

(4) Cleaning unit. Steel is sprayed with a caustic soltuion, rinsed, and dried.

(5) Furnace. Steel is heat treated for desired mechanical properties.

(6) Coating pot. Steel is coated with either Zn or $55 \% \mathrm{Al}-45 \% \mathrm{Zn}$.

(7) Cooling tower. Steel is cooled to near room temperature.

(8) Surface conditioning mill (SCM). Prepares the steel for painting.

(9) Tension leveler. Steel is slightly elongated for uniform flatness.

(10) Chemical treatment. Provides interim protection against coating deterioration during storage.

(11) Resin coater. Provides lubrication for roll forming, suppresses hand/foot prints during installation, and provides some corrosion protection.

(12) Exit accumulator tower.

(13) Exit tension reel.

Figure 10. Metal coil coating: metal coating line. (Figure courtesy of Steelscape 2003)

\section{Paint Line}

The paint line is similar to the metal coating line. In the paint line (Figure 11), a coil from the metal coating line is fed to the entry reel (stage 1) where coils are welded or stitched together for 
continuous operation of the line. The coil then passes though an accumulator tower and cleaner (stage 2) prior to chemical coating. The chemical coater (stage 3) pre-treats the surface to accept primer or paint and to provide corrosion resistance. A primer (stage 4) is then applied to the steel strip and cured in the prime oven. Then the strip is coated with the finish paint (stage 5) and cured in the finish oven. Paint lines can paint one or both sides of the strip, depending on customer requirement. The cured, painted steel is then quenched with water and cooled to room temperature (stage 6). Finally, rollers remove the excess water, and the steel goes into the exit accumulator (stage 7) before it is taken up onto an exit reel (stage 8). The finished strip can be sent back through the paint line if additional paint layers are desired. This is often done for print or pattern finishes where the final product includes multiple colors to mimic wood shakes, asphalt shingles or aged copper.

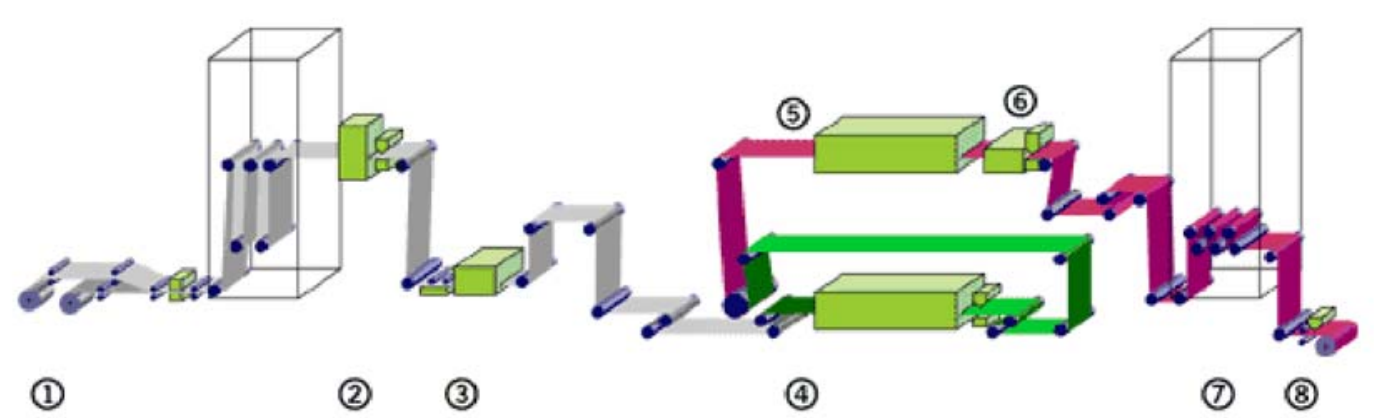

(1) Entry reels.

(2) Cleaning unit.

(3) Chemical coater. Applies an initial coating on the steel.

(4) Prime coater. Coats the steel with the primer.

(5) Finish coater. Coats the steel with the finish paint.

(6) Water quench. Painted steel is cooled down to room temperature.

(7) Exit accumulator.

(8) Exit reel.

Figure 11. Metal coil coating: paint. (Figure courtesy of Steelscape 2003)

\section{Metal forming plants}

Metal forming plants cut and press painted or unpainted metal coils to form either flat panels or simulations of non-metal roofing products (e.g., shake, shingle, tile, and slate). A very few fabricators apply granulated material to the painted panels in order to simulate asphalt shingles. However, most fabricators of shingle or tile type profiles use embossing or stamping to achieve the desired look. Some examples of metal roofing products are shown in Figure 12. 


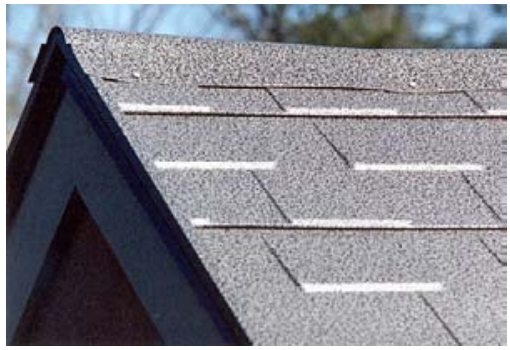

(a)

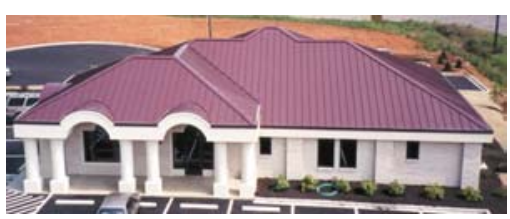

(d)

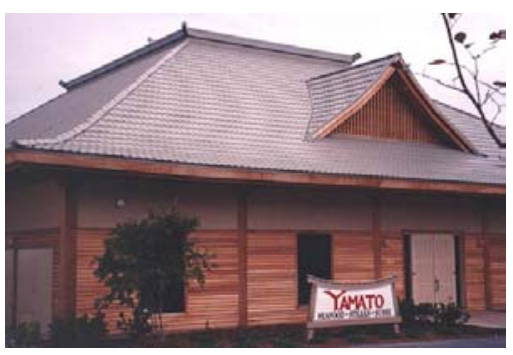

(g)

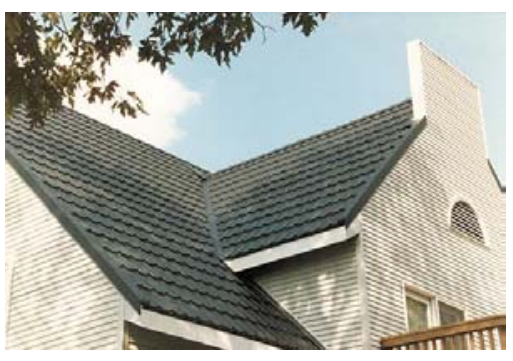

(j)

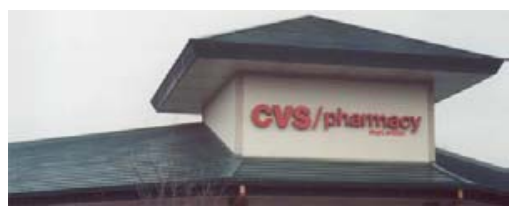

(b)

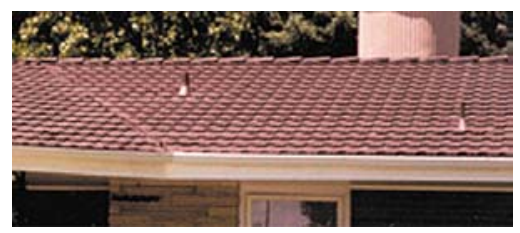

(e)

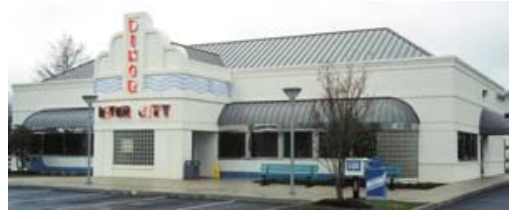

(h)

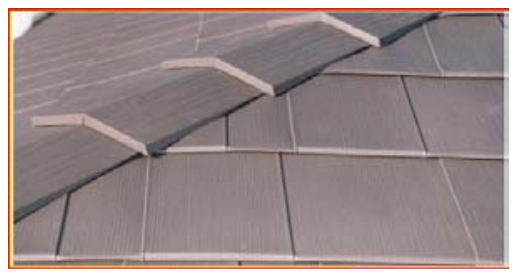

$(\mathrm{k})$

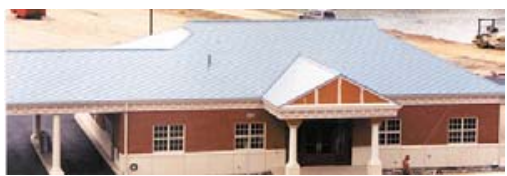

(c)

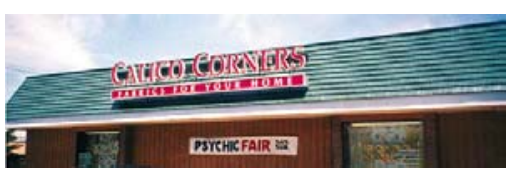

(f)

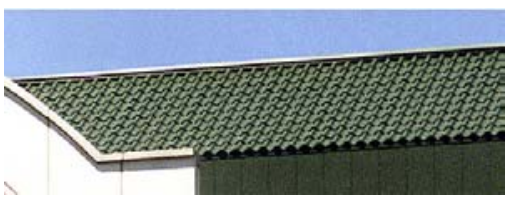

(i)

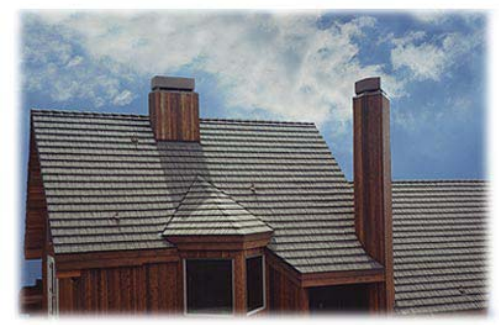

(1)

Figure 12. Simulated roofing products made from metal: (a) Advanta Shingles; (b) Bermuda Shakes; (c) Castle Top; (d) Dutch Seam Panel; (e) Granutile; (f) Perma Shakes; (g) Scan Roof Tile; (h) Snap Seam Tile; (i) Techo Tile; (j) Verona Tile; (k) Oxford Shingles; and (l) Timbercreek Shakes. Products a-j are manufactured by ATAS International, Inc., while products $k$ and $l$ are manufactured by Classic Products, Inc. (Photos courtesy of ATAS International and Classic Products) 


\section{Methods to Produce Cool Roofing Materials}

\section{Shingles}

The solar reflectance of a new shingle is dominated by the solar reflectance of its granules, since by design, the surface of a shingle is well covered with granules. Hence, we focus on the production of cool granules. There are primarily two ways to increase the solar reflectance of the granules: manufacturing granules from highly reflective (e.g., white) rocks, and/or coating the granules with reflective pigments. The use of naturally white rock is limited by local availability of suitable inert rocks, which are often not found in large quarries. Hence, manufacturers usually color the granules.

Until recently, the way to produce granules with high solar reflectance has been to use titanium dioxide $\left(\mathrm{TiO}_{2}\right)$ rutile, a white pigment. Since a thin layer of $\mathrm{TiO}_{2}$ is reflective but not opaque, multiple layers are needed to obtain the desired solar reflectance. This technique has been used to produce "super-white" (meaning truly white, rather than gray) granulated shingles with solar reflectance exceeding 0.5. Manufacturers have also tried to produce colored granules with high solar reflectance by using nonwhite pigments with high near-infrared (NIR) reflectance. However, like $\mathrm{TiO}_{2}$, cool-colored pigments are also partly transparent to NIR light; thus, any NIR light not reflected by the cool pigment is transmitted to the (typically dark) granule underneath, where it can be absorbed. To increase the solar reflectance of colored granules with cool pigments, multiple color layers, a reflective undercoating, and/or reflective aggregate should be used. Obviously, each additional coating increases the cost of production.

Figure 13 shows the iterative development of a cool black shingle. A conventional black roof shingle has a reflectance of about 0.04 . On the first try to increase the solar reflectance of the shingle, we replaced the standard black pigment on the granules with one that is NIR reflective. That increased the reflectance of the granule to 0.12 . On the second try, we used a two-layered technique where we first applied a layer of $\mathrm{TiO}_{2}$ white base (increasing the solar reflectance of the base granule to 0.28 ) and then a layer of NIR-reflective black pigment. This increased the reflectance of the black granule to 0.16 . On our third prototype, the base granule was coated in ultra-white (reflectance 0.44) and then with an NIR-reflective black pigment. This increased the solar reflectance to 0.18 . Figure 13 also shows the performance limit (reflectance 0.25 ) where a $25-\mu \mathrm{m}$ thick layer of NIR-reflective black coating is applied on an opaque white background.

The application of pigmented coatings to roofing granules appears to be the critical process step. Several layers of silicate coatings can be involved, and may include not just one or more pigments, but the use of clay additives to control viscosity, biocides to prevent staining, and process chemistry controls to avoid unreacted dust on the product.

One way to reduce the cost is to produce cool-colored granules via a two-step, two-layer process. In the first step, the granule is pre-coated with an inexpensive pigment that is highly reflective to NIR light. In the second step, the cool-colored pigment is applied to the pre-coated granules.

Shingles tend to lose some granules as they age and weather, exposing asphalt-coated fiberglass and reducing solar reflectance. Substituting a reflective sealant for the black asphalt could slow this. While developing such a replacement for asphalt may be of long-term interest, we do not see an easy or short-term solution to this problem. 
It should be noted that the reflectance of an asphalt shingle covered with granules will always be less than that of the granule's coating, since some of the light reflected by each granule will strike a neighboring granule and be absorbed. These "multiple reflections" can reduce shingle reflectance by as much as 0.15 .

Finally, the granule manufacturing and shingle manufacturing industries have designed their quality-control laboratories to test the visible color of their products. We anticipate that the industry will need to equip itself with additional instruments to test the solar reflectance and the NIR optical properties of their products. It is also envisioned that unified standards have to be developed to address issues related to manufacturing of cool-colored granules and shingles.

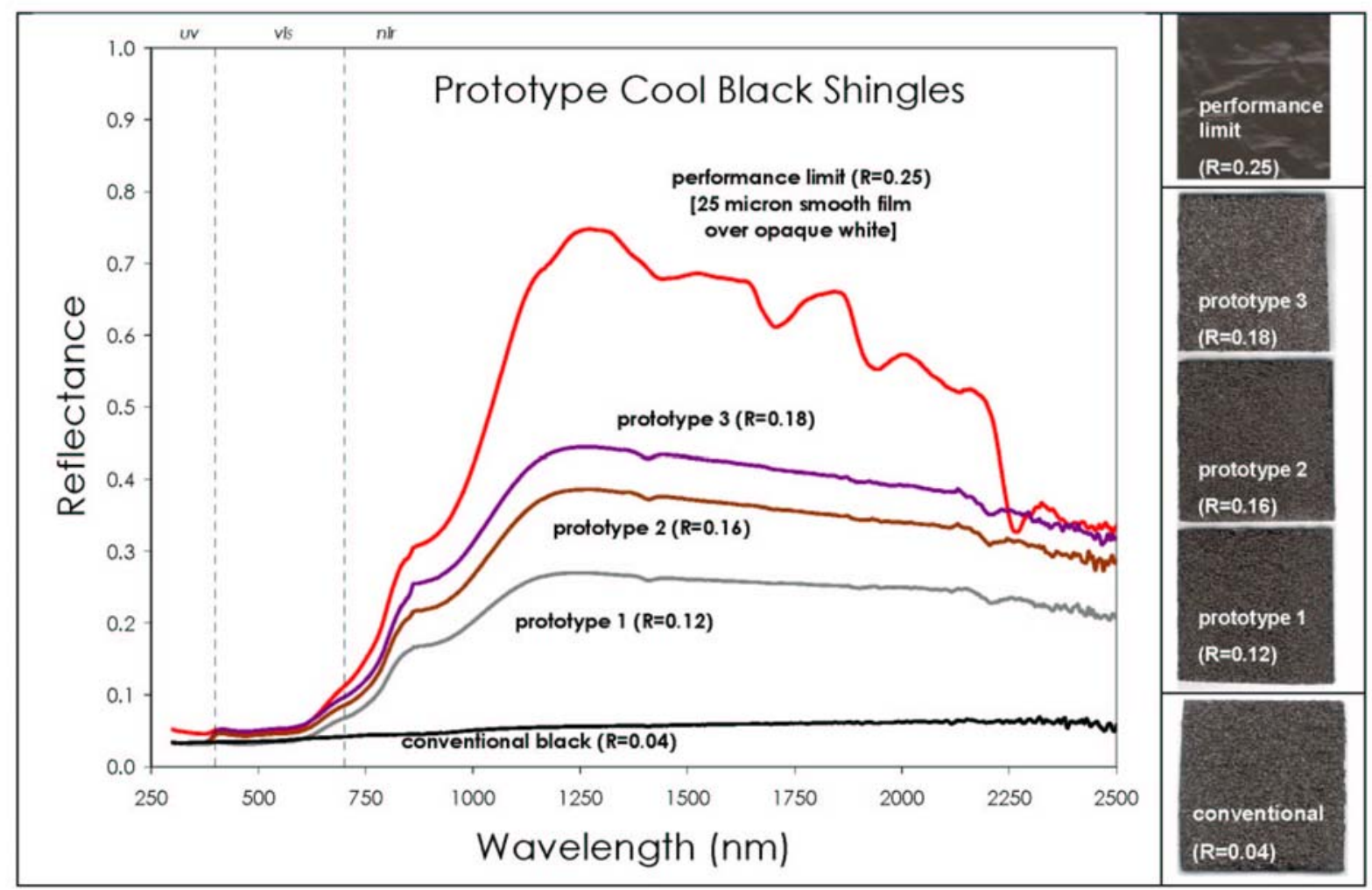

Figure 13. Development of a cool black shingle. $R=$ Solar reflectance.

\section{Clay tiles}

Considerations for production of cooler colored tiles are similar to those of the roofing shingles. Three ways to improve the solar reflectance of clay tiles are: (1) use of raw clay materials with low concentrations of iron oxides and elemental carbon; (2) use of cool pigments in the coating; and (3) application of the two-layered coating technique using pigmented materials with high solar reflectance as an underlayer. Although all these options are in principle easy to implement, they may require changes to current production techniques that may add to cost of the finished products. Colorants can be included throughout the body of the tile, or used in a surface coating. Both methods need to be addressed. 


\section{Concrete tiles}

There are three ways to improve the solar reflectance of colored concrete tiles. The first is to whiten the tile by using white cement in the concrete mix; using a white cementitious surface coating (during the pre-cure coating); and/or using white polymeric surface coating (during the post-cure coating). The second method is to use cool color pigments (infrared-scattering colored pigments) in the coating to provide choice of high-reflectance color. Examples of such cool colored pigments include mixed metal complex inorganic pigments. Cool pigments have been used successfully by a few leading and innovative tile-manufacturing companies. The third approach is to use cool pigments over a highly reflective undercoat. The undercoat must be allowed to properly dry before application of the topcoat. For example, near-infrared transparent phthalocyanine blue can be applied over a white undercoat to produce a cool blue tile.

Figure 14 shows the results of an effort to develop coatings for concrete tile roofs. Various coatings yielded a palette of cool colors each with solar reflectance exceeding 0.4 . In some of these prototypes (the blue and the black), cool colored coatings are applied over a white base coat.

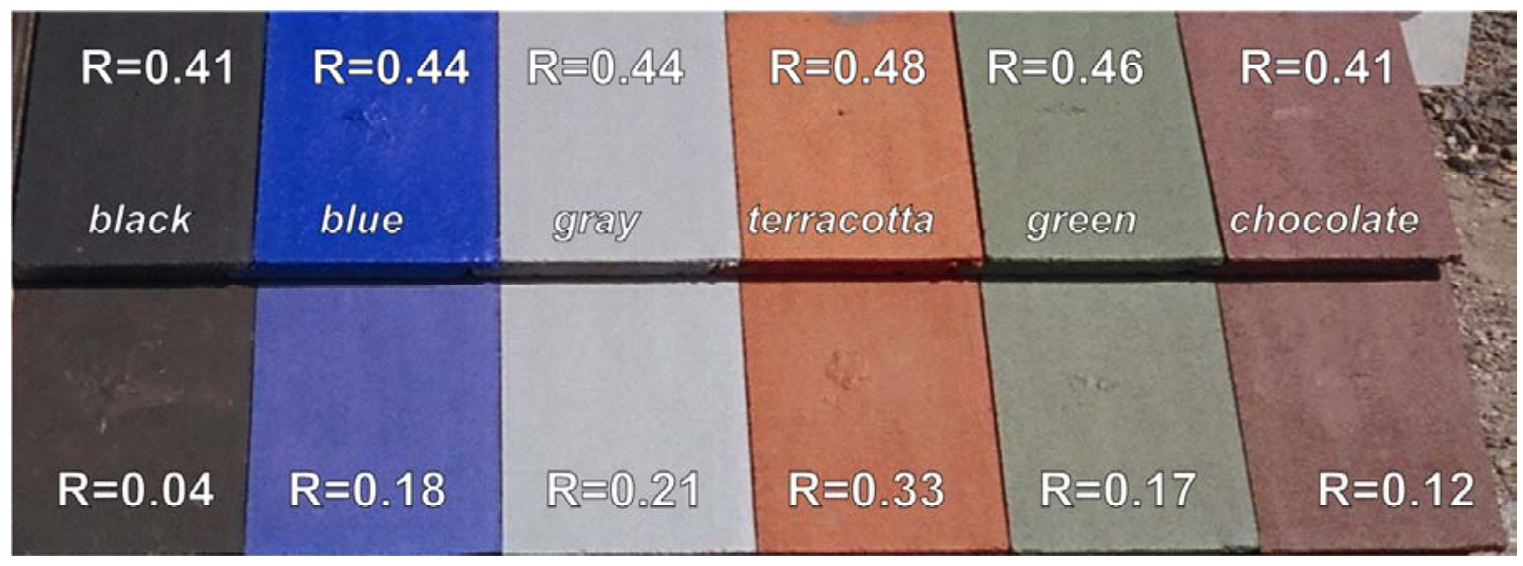

Figure 14. Solar reflectance $(R)$ of several prototype cool coatings for concrete tile roofs. (Image courtesy of American Rooftile Coatings)

\section{Metal panels}

Application of cool-colored pigments in metal roofing materials may require the least change to the existing production processes. As in the cases of tiles and asphalt shingle, cool pigments can be applied to metal via a single or a double-layered technique. If the raw metal is highly reflective, a single-layered technique may suffice. The coatings for metal shingles are thin, durable polymer materials. These thin layers use materials efficiently, but limit the maximum amount of pigment present. However, the metal substrate can provide some NIR reflectance if the coating is transparent in the NIR.

\section{Quality control}

The quality-control laboratories of colored roofing manufacturers are typically equipped to test the visual appearance (e.g., color) of their products. We anticipate that the industry will need to acquire instruments for testing the solar reflectance and NIR reflectances of their products. It is also envisioned that unified standards will have to be developed to address the initial reflectance, 
aged reflectance, mechanical properties, and thermal properties of cool-colored roofing materials.

\section{Conclusions}

Fiberglass roofing shingles, tiles, and metallic materials comprise over $80 \%$ (by roof area) of the U.S. western region residential roofing market. In cooling-dominated regions, increasing the solar reflectance of the roof lowers air-conditioning use in a cooled building and improves comfort in an unconditioned building.

Our analysis has suggested that cool-colored roofing materials can be manufactured using the existing equipment in production and manufacturing plants. The three principle ways to improve the solar reflectance of roofing materials including: (1) using of raw materials with high solar reflectance, (2) using cool pigments in the coating; and (3) applying a two-layered coloring technique using pigmented materials with high solar reflectance as an underlayer. Although all these options are in principle easy to implement, they may require changes to current production techniques that may add to cost and market competitiveness of the finished products.

Application of cool-colored pigments in metal roofing materials may require the least change to the existing production processes. As in the cases of tile and fiberglass shingle, cool pigments can be applied to metal via a single or a double-layered technique. If the raw metal is highly reflective, a single-layered technique may suffice.

Additional quality control measurements may be required to verify that coatings are truly NIRreflective.

\section{References}

ARMA. 1997. "Residential Asphalt Roofing Manual.” Asphalt Roofing Manufacturers Association, 4041 Power Mill Rd., Suite 404. Calverton, MD 20705. (301) 348-2002 FAX: (301) 348-2020. www.asphaltroofing.org

ASTM C 1167. 2003. "Standard Specification for Clay Roof Tiles," ASTM International. For referenced ASTM standards, visit the ASTM website, www.astm.org.

Brown, J.A. 1960. Granules. Chapter 19 of Industrial Mineral and Rocks. Ed. J.L. Gillson. American Institute of Mining, Metallurgical, and Petroleum Engineers. This reference provides a detailed overview of the manufacturing methods of colored granules.

DHHS (NIOSH). 2001. Publication No. 2001-127. Asphalt fume exposure during the manufacture of asphalt roofing products. United States Department of Health and Human Services (National Institute for Occupational Safety and Health). August. http://www.cdc.gov/niosh/pdfs/2001-127.pdf This document in detail describes various manufacturing methods for asphalt roofing products.

EPA. 1995. Compilation of Air Pollutant Emission Factors, AP-42, Fifth Edition, Volume I: Stationary Point and Area Sources. Chapter 11. United States Environmental Protection Agency. http://www.epa.gov/ttn/chief/ap42/ch11/final/c11s02.pdf

This document in detail describes various manufacturing methods and emissions from plants for asphalt roofing manufacturers.

Jewett, C.L., Collins, R.C., Weaver, L.W., and McShea, T. 1994. Roofing Granules. In Industrial Mineral and Rocks (Nonmetallics other than Fuels). Senior Ed. Donald D. Carr, American Institute of Mining, 
Metallurgical, and Petroleum Engineers. Society for Mining, Metallurgy, and Exploration, Littleton, $\mathrm{CO}$. This reference provides a detailed overview of colored granules manufacturing methods.

Joedicke, I. 1997. Iron oxides in roofing granules manufacture. Intertech Conferences. Iron Oxides 97 for Colorant \& Chemical Applications.

The paper discusses the production and coloring of roofing granules.

Joedicke, I. 2002. Roofing granules with a decorative metallic appearance. United States Patent Application Publications: US 2002/0187306 A1.

The patent briefly discusses the colored roofing granules and methods for preparation of granules with decorative metallic appearance.

Laaly, H.O. 1992. The Science and Technology of Traditional and Modern Roofing Systems. Laaly Scientific Publishing, Los Angeles, CA. This book provides an overview of the production and application of various roofing materials.

NPS. 2003. From asbestos to zinc, Roofing of Historic Buildings, National Park Services. http://www.cr.nps.gov/hps/tps/roofingexhibit/introduction.htm This site provides a historical background of several roofing materials including: asbestos-cement shingles, asphalt shingles, clay tile, composition (built-up roofing), metals, slate, and wood shingles.

Paris, N. and Chusid, M. 1999. Color in concrete: Beauty and Durability. (Reprint from Concrete International Magazine and the American Concrete Institute. http://www.daviscolors.com/literature/pdf/Durability.PDF The document discusses the color durability and cleaning methods for concrete.

Paris, N. and Chusid, M. 1997. Coloring systems. http://www.daviscolors.com/literature/pdf/COLORING.PDF

This document briefly describes methods for coloring concrete products using powder, liquid, and granules, and pigments.

Steelscape. 2003. http://www.steelscape.com/aboutsteelscape/phototour.html.

Western Roofing. 2002. 2002 Market Survey. pp 62-63, July/August.

Western Roofing. 2003. Roofing Up in the West. pp 61-67, January/February. 


\section{Appendix: Factories Visited for This Study}

We visited several California facilities that produce roofing materials of interest, including a fiberglass shingle factory, a roofing granule plant, a clay roofing tile factory, a concrete roofing tile factory, and a metal coil coating plant.

\section{Fiberglass shingle plant}

Elk Corporation, California Division

6200 Zerker Road, Shafter, CA 93263

This advanced, fully automated plant was built in 1993 and become operational in 1995. Elk buys and mixes 15 different colors of granules to produce roofing shingles in a variety of colors. At the Shafter plant, about 1200 tons of colored and 500 tons of uncolored granules are consumed each day in shingle production.

In addition to its main production line, the Shafter plant has a pilot line for limited production of special-order shingles. This pilot line may be useful when we wish to manufacture limited quantities of cool-colored roofing shingles for field testing.

The plant has a quality control laboratory to test the visual and mechanical properties of the shingles.

A virtual tour of the Elk plant is available online at

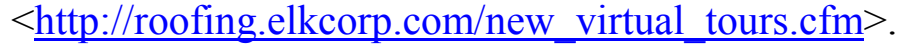

\section{Roofing granule plant}

ISP Granule Products, Inc.

1900 Highway 104, Ione, CA 95640

ISP acquired this plant in 2002. The plant is located near rock quarries, and can make both single-coat and multi-coat products.

The plant has a quality control laboratory to test the visual and mechanical properties of the granules.

\section{Metal coil coating}

Steelscape, Inc.

11200 Arrow Route, Rancho Cucamonga, CA 91730

Steelscape has four major production lines: a pickle line, where hot-band metal is uncoiled, cleaned and trimmed to a desired width; a cold mill line, where the coil is thinned to a desired thickness; a metallic coating line, where the coils are recleaned, a layer of metallic coating (zinc or zinc/aluminum alloy) is applied, and the surface is treated for painting or for use as a bare metal; and a paint line, where primer and finish layers are applied.

The plant has a quality control laboratory to test the visual, mechanical, and chemical properties of the painted and unpainted products.

A virtual tour of the Steelscape plant is available online at

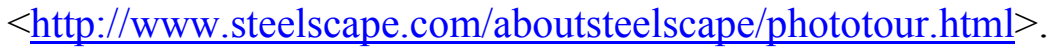




\section{Clay roofing tile plant}

Maruhachi Ceramics of America, Inc. (MCA)

1985 Sampson Avenue, Corona, CA 92879

MCA Tile is a modern clay tile manufacturing plant that supplies tiles to the western U.S. The facility and has five major operations: (1) mixing raw clay materials and preparing clay batt (dough); (2) extrusion molding of clay batt to form tiles; (3) air drying of raw tiles; (4) coloring tiles; and (5) kiln-firing colored tiles. MCA manufactures both glazed and unglazed colored tiles.

There is a quality control laboratory at the plant to test the visual and mechanical properties of the tiles. MCA has also a solar spectrum reflectometer (Devices \& Services) to measure the solar reflectance of the tiles.

More information on MCA Tile products is available online at $<$ http://www.mca-tile.com $>$.

\section{Concrete roofing tile plant}

\section{MonierLifetile}

\section{Roth Road, Lathrop, CA 95330}

MonierLifetile is a major manufacturer of concrete roof tiles with 12 plants spread throughout the country. The facility at Lathrop operates in three shifts - and has five major operations: (1) mixing raw sand and filler materials, (2) mixing the concrete mixture and colorants, (3) molding of concrete to form tiles, (4) pre-cure coating of the tiles, (5) air drying of tiles, (6) and post curecoating and coloring of tiles.

There is a quality control laboratory at the plant to test the visual and mechanical properties of the concrete tiles. The plant at the Lathrop did not have instruments to measure the solar reflectance of the tiles.

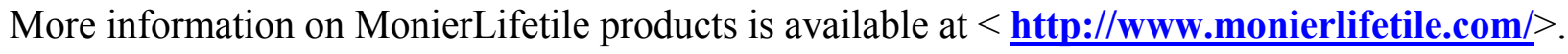

